\title{
General Certificate of Secondary Education performance in very low birthweight infants
}

\section{P O D Pharoah, C J Stevenson, C R West}

See end of article for authors' affiliations

Arch Dis Child 2003;88:295-298

...................

Correspondence to: Prof. P O D Pharoah, Emeritus Professor Research Associate Lecturer, FSID Unit of Perinatal and Paediatric Epidemiology, Department of Public Health, University of Liverpool, Liverpool L69 3GB, UK;

p.o.d.pharoah@liv.ac.uk

Accepted 29 September 2002
Aim: To compare children of very low birth weight with matched controls for their performance in the General Certificate of Secondary Education (GCSE).

Methods: GCSE examination results of 167 children of birth weight $\leqslant 1500 \mathrm{~g}$ attending mainstream schools and without clinical disability and 167 individually matched classroom controls were analysed. Results: In 143 instances, both children of a matched pair were entered for examination in one or more GCSE subjects. The total points score obtained was greater in the comparison group than in the index cases (difference between means $4.45: 95 \% \mathrm{Cl} 0.95$ to $7.94 ; \mathrm{p}=0.01$ ). The mean point score per examination subject was also significantly greater in the comparison group than in the index cases (mean of differences 0.43: $95 \% \mathrm{Cl} 0.12$ to $0.73 ; \mathrm{p}<0.01$ ).

Conclusions: As the children were closely matched for school and several social variables, factors acting during fetal or early postnatal development of very low birthweight infants probably compromise performance in the GCSE examination to a greater extent than school or childhood social environmental factors.
B irth weight is an important determinant of neonatal and infant mortality and childhood sensory and motor disabilities. ${ }^{1-4}$ Furthermore, low birthweight (LBW) children compared to children of normal birth weight perform less well on measures of cognitive functioning. In these reports, cognitive functioning has usually been assessed by formal measures of the Intelligence Quotient (IQ), such as the Wechsler Intelligence Scale for Children (WISC), ${ }^{5-7}$ British Ability Scales, ${ }^{8}$ and the McCarthy Scales of Children's Abilities. ' Tests of reading, arithmetic, and non-verbal reasoning also have been used. ${ }^{610^{11}}$ Less specific assessments of school performance have included teachers' rating of academic performance, need for remedial/special education classes, and school grade repetition. ${ }^{12}{ }^{13}$

The General Certificate of Secondary Education (GCSE) is a nationally administered examination taken by children, usually when they are aged about 16 years. Unlike formal IQ tests, often done for research purposes, the results of the GCSE examinations are of functional relevance to the child, as they may influence employers' selection criteria and are integral to the requirements for entering tertiary education.

The primary aim of the study reported here is to compare the GCSE results of a geographically defined cohort of very low birthweight infants (VLBW, $\leqslant 1500 \mathrm{~g}$ ) with a matched comparison group. A secondary aim was to examine the association between formal IQ tests administered at age 8 years with the achievement in the GCSE examination in the index and comparison groups.

\section{METHODS}

A cohort comprising all infants of birthweight $\leqslant 1500 \mathrm{~g}$ born in 1980 and 1981, to mothers resident in the county of Merseyside, was obtained from birth notifications. When aged 3 years, the children were examined to determine the prevalence of disability. ${ }^{14}$ At the 8 years of age follow up, for those children attending mainstream schools, an age and sex matched comparison from the same class in the same school was obtained. The WISC was applied to determine the IQ of children in both the index and comparison groups. ${ }^{6}$ The intention behind matching for school was that, because primary schools tend to draw children from socially homogeneous areas, it would effectively match for important social variables. This premise was tested at the 8 years of age follow up, when index and comparison children were compared for several socioeconomic variables, including social class, current employment status of the father, housing status of the family, parental education and income, and number of children in the family. All these indices were marginally in favour of better social circumstances for the comparison group, but none was statistically significant. The only statistically significant difference was that fewer index than comparison children were living with both natural parents. ${ }^{6}$

The children were reassessed when aged 15 years with, whenever possible, the same comparison group as at the 8 year follow up. The children now had moved from primary to secondary schools and in some instances the index children and their matched comparison children were at different secondary schools. If the original comparison child from primary school was not available, a new comparison child of the same sex, in the same class at secondary school, and nearest in birth date to the index child was selected.

When the cohort was aged 20 years, ethical permission was obtained to approach them again to obtain details of their employment and education record and to question them on their performance in the GCSE examinations. The data were confirmed by obtaining the GCSE results from the local education authorities or, in the case of those children attending private schools, from the school headmaster.

A numerical score was given to each grade of GCSE ranging from 8 for $A^{*}, 7$ for $A$ through to 1 for grade $G$. The number of subjects examined, the total points (sum of points obtained in all subjects examined), and the mean point score (total points obtained/number of subjects examined) were determined for each child.

Abbreviations: GCSE, General Certificate of Secondary Education; IQ, Intelligence Quotient; LBW, low birth weight; VLBW, very low birth weight; WISC, Wechsler Intelligence Scale for Children 
Table 1 GCSE examination results (143 matched pairs)

\begin{tabular}{llll}
\hline & Index group & $\begin{array}{l}\text { Comparison } \\
\text { group }\end{array}$ & $\begin{array}{l}\text { Comparison-index } \\
\text { Difference between means } \\
\text { (95\% Cl; } \mathrm{p} \text { value) }\end{array}$ \\
\hline Mean number of subjects examined & 7.91 & 8.15 & $0.24(-0.22$ to $1.69 ; \mathrm{NS})$ \\
Mean total points obtained & 32.33 & 36.78 & $4.45(0.95$ to $7.94 ; \mathrm{p}=0.01)$ \\
Mean points per subject examined & 3.83 & 4.26 & $0.43(0.12$ to $0.73 ; \mathrm{p}<0.01)$ \\
\hline NS, non-significant. & & & \\
\hline
\end{tabular}

Children attending "special" schools (schools for the deaf, blind, or educationally subnormal) and those with clinical disability were excluded from the analysis.

For the comparison of performance in individual subjects, analysis was made only if there were more than 20 instances where both members of a matched pair had sat the examination.

\section{Statistical methods}

Student's $t$ test for matched pairs was used when comparing GCSE total point scores, mean points per subject examined, and IQ test results in the index and comparison group of children.

Comparison of performance in individual subjects was assessed using the non-parametric Wilcoxon signed ranks test because the examination grades obtained were highly grouped.

Linear regression using SPSS was applied to examine the association between IQ at age 8 years and subsequent achievement in the GCSE examination.

\section{RESULTS}

\section{Survey population}

There were 40321 live births in Merseyside in 1980-81; 399 were of birth weight $\leqslant 1500$ g, of whom 219 survived to age 15 years. Of the 219 survivors, $10(4.6 \%)$ of the index cases refused assessment, were abroad, or could not be traced. Forty two children attending special schools or with a clinical disability were excluded. There were 167 index children free of clinical disability and attending mainstream schools with a sex, school, and class within school matched comparison child. In 74 (44.3\%) of the 167 matched pairs, the index and the comparison child attended the same primary and secondary schools; in 56 (33.5\%) instances the index and comparison child had attended the same primary school but were at different secondary schools; in $37(22.2 \%)$ a new comparison child attending the same secondary school as the index child was obtained.

Of the 167 matched pairs, 151 index and 158 comparison children were examined in one or more GCSE subjects. Sixteen $(9.6 \%)$ index and nine $(5.4 \%)$ comparison children were not entered for the examination by the school, were absent, or were excluded for social reasons. In 143 of the 167 matched pairs, both members of a pair had sat at least one GCSE examination subject.

\section{GCSE performance}

Table l shows the index and comparison groups' performance in the GCSE examinations. The comparison group sat an examination in more subjects than the index group, but the difference was not statistically significant. However, the total points obtained were significantly greater in the comparison than the index group. This difference was predominantly because the comparison group obtained a higher mean score for each subject examined than the index group. The difference between the means was 0.43 (95\% CI 0.12 to 0.73 ; $\mathrm{p}<0.01)$ points. In terms of examination grades, this is almost half a grade difference per subject between the groups. The comparison group obtained a mean subject result of between grade $\mathrm{C}$ and grade $\mathrm{D}$, while the index group was between grade $\mathrm{D}$ and grade $\mathrm{E}$.

Table 2 compares the performance in individual examination subjects. The comparison group of children performed significantly better than the index children in only Mathematics and Statistics. In Science A and Science B, English, and English Literature examinations, the comparison group obtained better grades than the index group, but the differences were not statistically significant. In History and Geography examinations, both groups had very similar examination grades.

Science A and Science B are composite examinations, and it is usual school policy to encourage the more able students to sit the sciences of biology, chemistry, and physics as independent subjects. Among the comparison children, 19 took Biology, 18 took Chemistry, and 17 took Physics; the corresponding figures for the index children were 9, 8, and 8 respectively. The difference between the comparison and index children is highly significant (Mantel Haenszel $\chi^{2}=10.7 ; \mathrm{p}=0.001$ ).

For comparative purposes, national GCSE results are usually published as the proportion of children entered for the examination who achieve five or more subjects at grade $\mathrm{C}$ or better. In 1997, the national average was $45.1 \%$. For the index children it was $38.4 \%$ and for the comparison group, $44.3 \%$.

\begin{tabular}{|c|c|c|c|c|c|}
\hline Subject & $\begin{array}{l}\text { Number of } \\
\text { paired results } \\
(100 \%)\end{array}$ & $\begin{array}{l}\text { Index child obtained } \\
\text { better grade than } \\
\text { comparison child (\%) }\end{array}$ & $\begin{array}{l}\text { Comparison child } \\
\text { obtained better } \\
\text { grade than index } \\
\text { child (\%) }\end{array}$ & $\begin{array}{l}\text { Number of } \\
\text { pairs with } \\
\text { equal grade } \\
\text { (\%) }\end{array}$ & $\begin{array}{l}\text { Wilcoxon } \\
\text { signed } \\
\text { ranks test } \\
p \text { value }\end{array}$ \\
\hline Science A & 109 & 38 (34.9\%) & $43(39.4 \%)$ & $28(25.7 \%)$ & 0.35 (NS) \\
\hline Science B & 87 & 31 (35.6\%) & $34(39.1 \%)$ & $22(25.3 \%)$ & 0.60 (NS) \\
\hline Maths/statistics & 127 & $40(31.5 \%)$ & $63(49.6 \%)$ & 24 (18.9\%) & 0.004 \\
\hline English & 129 & 45 (34.9\%) & 61 (47.3\%) & $23(17.8 \%)$ & 0.19 (NS) \\
\hline English Literature & 83 & $25(30.1 \%)$ & $42(50.1 \%)$ & $16(19.3 \%)$ & 0.07 (NS) \\
\hline History & 21 & $8(38.1 \%)$ & $8(38.1 \%)$ & $5(23.8 \%)$ & 0.67 (NS) \\
\hline Geography & 28 & $11(39.3 \%)$ & $10(35.7 \%)$ & $7(25.0 \%)$ & 0.81 (NS) \\
\hline
\end{tabular}




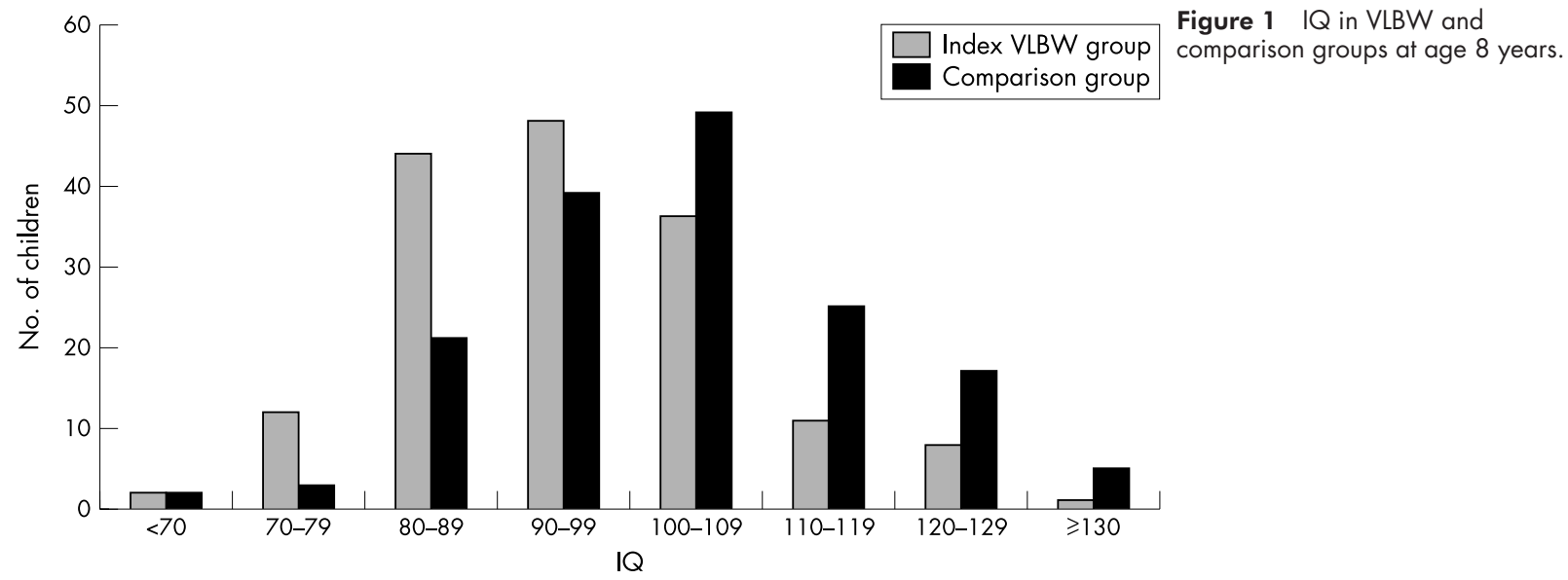

\section{Association between IQ and GCSE performance}

The comparison group performed significantly better on the IQ test when aged 8 years. Figure 1 shows the frequency distribution of IQ in the comparison group shifted to the right compared with the index group. The matched paired $t$ test showed a mean difference in IQ of 7.55 (95\% CI 5.24 to 9.85).

For both index and comparison children there were highly significant correlations between IQ at age 8 and mean points score in the GCSE examination (index group correlation coefficient $r=0.65, \mathrm{p}<0.001$; comparison group correlation coefficient $r=0.53, \mathrm{p}<0.001)$.

The prediction of the mean points score for the index children was:

$$
(\mathrm{IQ} \times 0.077)-3.64 \text { (standard error 1.17) }
$$

Applying this to a child with an IQ of 100, an estimate of the mean points score in the GCSE would be 4.1 (95\% CI 1.8 to 6.4).

Similarly, the predicted mean points score for the comparison children was:

$$
(\mathrm{IQ} \times 0.058)-1.81 \text { (standard error 1.32) }
$$

The estimate for mean points score for a child with an IQ of 100 would be 4.0 (95\% CI 1.4 to 6.6 ).

Thus in both index and comparison children, an IQ of 100 predicts that the child will obtain a mean of grade $\mathrm{D}$ in the subjects examined. Although the IQ has very similar predictive value in both index and comparison children, the better GCSE performance of the comparison children is associated with their higher IQ compared to the index children.

\section{DISCUSSION}

Several follow up studies of cognitive performance as determined by measures of IQ have shown that LBW children perform less well than normal birth weight controls. $^{5-8}$ However, IQ is an artificial construct influenced by socially determined abilities and is not generally used to influence employers or selection for entry to further education. In contrast, performance in the GCSE examination is of major relevance in these contexts. We have shown here that, not only do VLBW compared to normal birth weight children have a significantly lower IQ measured at age 8 years, but they also perform less well in the GCSE examinations at age 16 years. Therefore, it is probable that the disadvantages in cognition associated with being of VLBW will persist well into adulthood.

It is of fundamental importance to determine at what stage in the child's development, from conception to adolescence, LBW has a disadvantageous effect on cognitive function. Such knowledge will influence the preventive strategies that should be pursued. As the comparison group were of the same sex and from the same class within a school, it is improbable that education methods or school selection policies for the child being entered for the GCSE examination account for the difference in GCSE performance.

The social indices examined when the children were aged 8 years showed that the comparison group had marginally better social conditions than the index children. ${ }^{6}$ Although the effect of these marginal differences must not be discounted, the probability that they have a major role in the difference in GCSE performance of the index and comparison groups is lessened. Other follow up studies of LBW children have also observed that matching for a variety of social indices does not nullify the difference in cognitive ability between LBW children and their controls. ${ }^{89111516}$

Birth weight is a composite function of gestational age and fetal growth. Disassociating the independent effects of these two components is difficult. The role of fetal growth on subsequent cognitive development is contentious. A national study concluded that impaired fetal growth was not associated with poorer cognitive performance in adult life. ${ }^{17} \mathrm{~A}$ small study also noted that, while birth weight had a significant effect on cognitive function, being small for dates had no effect. ${ }^{9}$ In contrast, other studies have noted that fetal growth may influence subsequent adult cognitive function, ${ }^{18}$ and that IQ at 8 years was associated with the degree of fetal growth restriction. ${ }^{19}$ In the data we report here, the index VLBW cases were defined by an upper birth weight limit of $1500 \mathrm{~g}$; therefore, the cohort will have contained a disproportionate number of infants who were growth restricted in utero. This will have enhanced the probability of detecting the effect of fetal growth on subsequent cognitive function.

The independent effects of severe malnutrition and social deprivation during the period of rapid brain growth in early infancy on subsequent mental development are difficult to disentangle. Nevertheless, the problem of maintaining an adequate energy intake in VLBW infants may compromise subsequent intellectual development. Preterm delivery influences plasma hormonal concentrations; in particular, low triiodothyronine concentrations in preterm infants are associated with IQ levels measured at 8 years of age. ${ }^{20}$

The poorer GCSE performance of VLBW children compared with their classroom matched controls, has implications for subsequent further education and employment. It is probable that the mediator of the cerebral impairment operates during fetal or early postnatal development during the phase of rapid brain growth to a greater extent than the social environmental or school educational factors. 


\section{ACKNOWLEDGEMENTS}

We would like to thank the the children, parents, and school staff in this study for their excellent cooperation. The study was funded by the British Heart Foundation and the Regional R\&D fund.

\section{Authors' affiliations}

P O D Pharoah, C J Stevenson, C R West, FSID Unit of Perinatal and Paediatric Epidemiology, Department of Public Health, University of Liverpool, Liverpool L69 3GB, UK

\section{REFERENCES}

1 Pharoah POD, Alberman ED. Mortality of low birth weight infants in England and Wales 1953 to 1979 . Arch Dis Child 1981.56:86-9.

2 Kiely JL, Stein Z, Susser M. Mortality and neurological impairment in low birthweight infants. Dev Med Child Neurol 1981;23:650-9.

3 Stewart AL, Reynolds EOR, Lipscomb AP. Outcome for infants of very low birthweight: survey of the world's literature. Lancet 1981;i:1038-41.

4 Escobar GJ, Littenberg B, Petitti DB. Outcome among surviving very low birth weight infants: a meta-analysis. Arch Dis Child 1991;66:202-12.

5 Marlow N, D'Souza SW, Chiswick ML. Neurodevelopmental outcome in babies weighing less than $2001 \mathrm{~g}$ at birth. BM 1987;294:1582-6.

6 Pharoah POD, Stevenson CJ, Cooke RWI, et al. Clinical and subclinical deficits at 8 years in a geographically defined cohort of low birth weight infants. Arch Dis Child 1994;70:264-70.

7 Horwood LJ, Mogridge N, Darlow BA. Cognitive, educational, and behavioural outcomes at 7 to 8 years in a national very low birthweight cohort. Arch Dis Child Fetal Neonatal Ed 1998;79:F12-F20.

8 Lloyd BW, Wheldall K, Perks D. Controlled study of intelligence and school performance of very low-birth weight children from a defined geographical area. Dev Med Child Neurol 1988;30:36-42.
9 Abel Smith AE, Knight-Jones EB. The abilities of very low-birthweight children and their classroom controls. Dev Med Child Neurol 1990;32:590-601

10 Marlow N, Roberts L, Cooke R. Outcome at 8 years with birth weights of $1250 \mathrm{~g}$ or less. Arch Dis Child 1993;68:286-90.

11 Richards M. Hardy R, Kuh D, et al. Birth weight and cognitive function in the British 1946 birth cohort: longitudinal population based study. BM 2001;322:199-203.

12 Eilers BL, Desai NS, Wilson MA, et al. Classroom performance and social factors of children with birth weights of 1,250 grams or less: follow-up at 5 to 8 years of age. Pediatrics 1986;77:203-8.

13 Buck GM, Msall ME, Schisterman EF, et al. Extreme prematurity and school outcomes. Paediatr Perinat Epidemiol 2000;14:324-31.

14 Powell TG, Pharoah POD, Cooke RWI. Survival and morbidity in a geographically defined population of low birthweight infants. Lancet 1986;i:539-43.

15 Hall A, McCleod A, Counsell C, et al. School attainment, cognitive ability and motor function in a total Scottish very-low-birth weight population at eight years: a controlled study. Dev Med Child Neurol 1995;37: 1037-50.

16 Herrgård E, Luoma L, Tuppurainen K, et al. Neurodevelopmental profile at five years of children born at $\leqslant 32$ weeks gestation. Dev Med Child Neurol 1993;35:1083-96.

17 Martyn CN, Gale CR, Sayer AA, et al. Growth in utero and cognitive function in adult life: follow up study of people born between 1920 and 1943. BM 1996:312:1393-6.

18 Sorensen HT, Sabroe S, Olsen J, et al. Birth weight and cognitive unction in young adult life: historical cohort study. BM 1997;315:401-3

19 Hutton JI, Pharoah POD, Cooke RWI, et al. Differential effects of preterm birth and small for gestational age on cognitive and motor development. Arch Dis Child Fetal Neonatal Ed 1997;76:F75-F81.

20 Lucas A, Morley R, Fewtrell M. Low triiodothyronine concentration in preterm infants and subsequent intelligence quotient (IQ) at 8 year follow up. BM 1996;312:1132-3

\section{ARCHIVIST}

\section{Thrombocytopenia-absent radius syndrome}

T he thrombocytopenia-absent radius (TAR) syndrome is characterised by bilateral absence of the radius with both thumbs present (absent thumbs suggests other syndromes) and

thrombocytopenia which may be transient and tends to remit in later childhood but is usually symptomatic in early infancy (90\% within the first 4 months). The main conditions which might be mistaken for TAR syndrome are Holt-Oram syndrome, Roberts syndrome, Fanconi anaemia, thalidomide embryopathy, and Rapadilino syndrome. TAR syndrome was first described by Shaw and Oliver in 1959. A series of 34 patients has been reported from South West England (Greenhalgh KL and colleagues. J Med Genet 2002;39:876-81).

The 34 patients were recruited through Clinical Genetics Services and all had bilateral absence of the radius with thumbs and documented thrombocytopenia (platelets $<150 \times 10^{9} \%$ L). Platelet count at birth ( 17 cases) ranged from $7 \times 10^{9}$ to $92 \times 10^{9}$ per litre.

The thumbs, though present, were always either hypoplastic or proximally placed. Details of the upper limb abnormalities are provided for 28 cases. Most (20) had relatively mild malformation with hypoplasia of ulna and humerus, normal shoulder girdle and normal strength. Five had more marked limb shortening with underdevelopment of the shoulder girdle and reduced strength and three had severe shortening of ulna and humerus and phocomelia. Thirteen of the 28 had lower limb abnormalities including small patella, knee subluxation, and severe leg bowing associated with abnormalities of hips, knees, and ankles.

Cow's milk intolerance with vomiting, diarrhoea, and failure to thrive affected almost half $(14 / 30)$ and was severe, requiring total parenteral nutrition, in two. Other associated abnormalities included renal anomalies (7), cardiac anomalies (5), and dysmorphic facial feature (16). Eight cases had a central facial capillary haemangioma, a feature not previously described in TAR syndrome. Thirteen probands had 20 siblings, four of whom were affected (empirical recurrence risk 20\%, "to be interpreted with caution"). Twenty-seven of the 34 subjects were female.

Chromosome analysis, done in 16 cases, showed an abnormality in two (a duplication in chromosome 8 and a translocation involving chromosomes 1 and 7) both of uncertain significance. The pattern of inheritance remains unclear. 